\title{
Terrorismo, Globalização e Transições Históricas
}

\author{
Terrorismo, Globalización y Transiciones Históricas \\ Terrorism, Globalization and Historical Transitions
}

\author{
Tânia Regina Zimmermann ${ }^{1}$ \\ Márcia Maria de Medeiros²
}

\begin{abstract}
Resumo
Este artigo propõe discutir as questões relacionadas ao terrorismo e à globalização a partir da lógica do pensamento postulada por autores como Zygmunt Bauman, Guy Debord e Eric Hobsbawm. Para isso, procura entender o significado do entrelaçamento entre terrorismo e globalização como elementos que fazem parte do processo de transição histórico levando em consideração a espetacularização desses atos no mundo ocidental, entendendo-os como uma forma de crítica a falência do sistema de valores proposto pelo modo de produção capitalista. Nesse sentido, ele entende que a sociedade ocidental baseia-se em relações sociais frágeis, baseadas no trópus da modernidade, que são construídas através da disseminação de informações através da Internet. Essa disseminação de informações cria a falsa ideia da dissolução das fronteiras, quando de fato o que vemos é o processo inverso e o reforço do conservadorismo nas formas de pensamento.
\end{abstract}

Palavras-chave: Sociedade do espetáculo; Fragmentação; Pós-Modernidade.

\section{Resumen}

Este artículo propone discutir las cuestiones relacionadas con el terrorismo y la globalización a partir de la lógica del pensamiento postulada por autores como Zygmunt Bauman, Guy Debord y Eric Hobsbawm. Para ello, procura entender el significado del entrelazamiento entre terrorismo y globalización como elementos que forman parte del proceso de transición histórico teniendo en cuenta la espectacularización de esos actos en el mundo occidental, entendiéndolos como una forma de crítica a la quiebra del sistema de valores propuesto por el modo de producción capitalista. En ese sentido, él entiende que la sociedad occidental se basa en relaciones sociales frágiles, basadas en el trópulo de la modernidad, que se construyen a través de la difusión de información a través de Internet. Esta diseminación de informaciones crea la falsa idea de la disolución de las fronteras, cuando de hecho lo que vemos es el proceso inverso y el refuerzo del conservadurismo en las formas de pensamiento.

Palabras clave: Sociedad del espectáculo. Fragmentación. Posmodernidad.

\begin{abstract}
This paper proposes to discuss the issues surrounding terrorism and globalization from the logic of thought that is postulated by authors such as Zygmunt Bauman, Guy Debord and Eric Hobsbawm. To do so, it seeks to understand the meaning of the interweaving between terrorism and globalization as elements that are part of historical transition processe taking into account the spectacularization of these acts in the Western world, understanding them as a form of criticism the bankruptcy of the value system Proposed by the capitalist mode of production. In this sense, he understands that Western society is based on fragile social relations, based on the modernity's trópus, which are constructed through the dissemination of information through the Internet. This
\end{abstract}

\footnotetext{
${ }^{1}$ Doutora em História; Professora titular da Universidade Estadual de Mato Grosso do Sul; Campo Grande, Mato Grosso do Sul, Brasil; E-mail: tania22@uems.br.

${ }^{2}$ Doutora em Letras; Professora da Universidade Estadual de Mato Grosso do Sul; Campo Grande, Mato Grosso do Sul, Brasil; E-mail: medeirosmarciamariade@ hotmail.com.
} 
dissemination of information creates the false idea of the dissolution of borders, when in fact what we see is the reverse process and the reinforcement of conservatism in the forms of thought.

Keywords: Society of the spectacle. Fragmention. Postmodernity.

\section{Introdução}

No dia 11 de setembro de 2001 a história registrou um dos momentos mais marcantes da caminhada do ser humano sobre a terra desde a invenção da escrita: os Estados Unidos foram vítima de um ataque terrorista, promovido pelo grupo extremista Al-Qaeda que resultou na queda das Torres Gêmeas na cidade de Nova Iorque. Noam Chomsky comenta sobre o assunto que:

As horripilantes atrocidades cometidas em 11 de setembro são algo inteiramente novo na política mundial, não em sua dimensão ou caráter, mas em relação ao alvo atingido. Para os Estados Unidos, é a primeira vez, desde a Guerra de 1812, que o território nacional sofre um ataque, ou mesmo é ameaçado (CHOMSKY, 2002, pp. 11-12).

Seis anos depois, o historiador inglês Eric Hobsbawm escreveu que o século XX foi sem sombra de dúvida, um dos momentos mais marcantes da história, pois combinou “(...) catástrofes humanas de dimensões inéditas, conquistas materiais substanciais e um aumento sem precedentes da nossa capacidade de transformar e talvez destruir o planeta (...)" (HOBSBAWM, 2007, p. 09). Ainda na opinião do autor, a globalização e todos os seus efeitos tem primordial importância para o entendimento deste contexto.

Mas qual o significado deste fenômeno para as questões que tangenciam o nosso tempo, entre elas o terrorismo, a pós-modernidade e a ideia de estarmos vivendo uma fase de transição histórica inerente ao colapso das instituições tais como nós as conhecemos?

É preciso salientar que esta globalização, marcadamente tecnológica e sob a égide da internet trouxe consigo as marcas do universo virtual (LEVY, 2011) e da cibercultura, conceito esse entendido por Levy como um "conjunto de técnicas (materiais e intelectuais), de práticas, de atitudes, de modos de pensamento e de valores que se desenvolvem juntamente com o crescimento do ciberespaço" (1999, p. 17).

Nesse sentido, o ciberespaço é ambiente privilegiado para o desenrolar de encontros e embates culturais, devido ao seu caráter essencialmente desterritorializante, sem fronteiras geográficas e físicas do mundo real, "de uma compreensão polifônica e heterogenética da subjetividade" (GUATTARI, 2012, p. 16). Levy reforça esta ideia ao preconizar que neste 
espaço encontramos outros pontos de territorialidade e de interação societária: "Uma comunidade virtual é construída sobre as afinidades de interesses, de conhecimentos, sobre projetos mútuos, em um processo de cooperação ou de troca, tudo isso independentemente das proximidades geográficas e das filiações institucionais" (LÉVY, 1999, p. 127).

Porém, esse processo facilitou a disseminação das comunicações e deixou clara as dimensões das desigualdades socioeconômicas entre as nações e mesmo no interior delas. A criação dos grandes blocos econômicos (NAFTA, MERCOSUL, Comunidade Comum Europeia), parecia uma tendência que facilitaria o desenvolvimento da coletividade ${ }^{3}$.

Esta lógica de pensamento poderia permitir uma diluição das fronteiras territoriais as quais já haviam sido abaladas pelo advento da comunicação tendo por base a internet. No entanto, o ano de 2016 assistiu a saída da Inglaterra do Mercado Comum Europeu; e o ano de 2017 viu a eleição de Donald Trump para a presidência dos Estados Unidos, bem como a sua vontade de construir um muro que impedisse os mexicanos de atravessarem a fronteira para entrar naquele país.

Práticas como estas, somadas a outras questões as quais o mundo assistiu estarrecido como, por exemplo, o fechamento das fronteiras europeias aos imigrantes sírios traz como mote o abalo aos direitos humanos. Fica clara diante deste contexto uma premissa: a internet espalha informação e serve como um potente elemento de dissolução virtualmente falando. No entanto, na prática, se reforça a lógica orquestrada por Umberto Eco, segundo a qual: “A vida política, entrando em crise, se subdividirá numa série de subsistemas autônomos e independentes do poder central, com milícias mercenárias e administração autônoma da justiça” (ECO, apud, ALVES, 1995, p. 163).

A questão primordial aqui, parafraseando Hobsbawm (2007), é que as desigualdades socioeconômicas que a globalização marcadamente apontou, constitui em importantes bases para as tensões que o mundo tem vivido. Somem-se a isso as tensões de cunho religioso motivadas por grupos radicais como o Talibã e a Al-Qaeda. Neste cenário vemos que as populações menos favorecidas são as que mais sofrem com os impactos provocados pela

3 Esta opção, no entanto, esqueceu-se de levar em conta as diferenças existentes dentro dos próprios conglomerados que levaram ao surgimento dos blocos econômicos. 
globalização entre eles a violência, processo esse que pode ser comprovado pela guerra na Síria.

De acordo com Alain Minc, este novo procedimento se relaciona às práticas de um novo "medievalismo" a diferença de que, neste caso não existe uma fé universal (no caso da idade média, a cristã) que sirva como elemento fundador das formas de ver o mundo e de ser no mundo, vigentes no tempo histórico. O que se pode observar é o crescimento de práticas supersticiosas (haja vista o radicalismo dos grupos supracitados e o conservadorismo mandante que ataca as conquistas sociais das ditas minorias) que parecia haver desaparecido, quando estavam apenas adormecidas (MINC, apud, ALVES, 1995, p. 163).

Para Stuart Hall (2006) a globalização é um movimento de processos e de forças as quais estão promovendo o deslocamento das identidades nacionais. Em grande parte isso se deve ao fato de que, no mundo globalizado existe uma integração (mesmo forçada) das comunidades e das instituições, as quais recombinam suas experiências e realidades promovendo um rearranjo dos conceitos de espaço e de tempo:

Que impacto tem a última fase da globalização sobre as identidades nacionais? Uma das suas características é a "compressão espaço-tempo", a aceleração dos processos globais, de forma que se sente que o mundo é menor e as distâncias mais curtas, que os eventos em um determinado lugar tem um impacto imediato sobre pessoas e lugares situados a uma grande distância (HALL, 2006, p. 69).

Na opinião de Eric Hobsbawm (2007) a globalização promoveu avanços em quase todos os setores: economia, tecnologia, cultura, entre outros. No entanto, “(...) do ponto de vista político e militar, os Estados territoriais continuam a ser as únicas autoridades efetivas" (HOBSBAWM, 2007, p. 28) e dentre todos os Estados, aquele que tem mais preponderância são os Estados Unidos, o que não quer dizer que ele possa garantir o controle e a segurança necessária àqueles e àquelas que vivem dentro das suas fronteiras, haja vista o 11 de setembro.

Esta premissa significa pensar no delicado fio condutor que equilibra as perspectivas nacionais, os processos globalizantes e os atos terroristas, os quais ganham visibilidade em uma sociedade que aprendeu com bastante afinco o sentido do espetáculo conforme preconizado por Guy Debord (2003). Daí a necessidade de se discutir estas questões de história recente e as movimentações históricas globais, bem como os novos agenciamentos 
advindos das relações humanas. Neste contexto, as questões inerentes ao terrorismo estão envolvidas.

As discussões conceituais bem como suas problematizações devem acompanhar esse movimento da história e, para isso, observamos que na definição comum do dicionário Aurélio, terrorismo apresenta dois significados, "1. Modo de coagir, ameaçar ou influenciar outras pessoas ou de impor-lhes a vontade pelo uso sistemático da força. 2. forma de ação política que combate o poder estabelecido mediante o emprego da violência” (AURÉLIO, p. 632).

Salienta-se porém, que o termo é polissêmico devido a existência de diferentes ações, configurações regionais e internacionais, diferentes modus operandi e organizações específicas cujas mudanças podem ser rápidas. Muitos grupos também não se autodenominam como terroristas embora, por suas ações, possam ser enquadrados dessa forma de acordo com as lógicas conceituais e de definição vigentes. Academicamente falando, de acordo com o Dicionário de Política, terrorismo pode ser assim definido:

[...] é a estratégia escolhida por um grupo ideologicamente homogêneo, que desenvolve sua luta clandestinamente entre o povo para convencê-lo a recorrer a: 2) ações demonstrativas que têm, em primeiro lugar, o papel de 'vingar' as vítimas do terror exercido pela autoridade e, em segundo lugar, de "aterrorizar" esta última, mostrando como a capacidade de atingir o centro do poder é o resultado de uma organização sólida e 3) de uma mais ampla possibilidade de ação: através de um número cada vez maior de atentados (veja -se a sua sucessão nos anos de 1878 a 1881 na Rússia) que simboliza o crescimento qualitativo e também quantitativo do movimento revolucionário (BOBBIO et al, 2000, p. 125).

Para Hobsbawm, a associação do terror como algo necessário anelante a processos revolucionários para alcançar determinados fins tem suas marcas instauradas a partir de 1798 e é a partir desta premissa que grande parte dos grupos terroristas a partir de então, buscam a sua justificação. Em sua obra "Globalização, Democracia e Terrorismo" este autor observa três momentos que associam atos terroristas com a violência política, quais sejam: nas décadas de 1960-70 onde ocorreram várias tentativas de derrubada de governos geralmente com fins nacionalistas; na década de 1980 cujas ações eram em grande parte de caráter religioso; e no início de nosso século no qual as táticas terroristas possuem caráter global e espetacular (HOBSBAWM, 2007). 
Em uma perspectiva da história recente sobre o terrorismo Leonardo Boff assim o define: "é toda violência espetacular, praticada com o propósito de ocupar as mentes com medo e pavor. (2014, p. 1). Para este autor, deve-se contemplar que o terrorismo não é um fenômeno da guerra, mas da política: "O terrorismo irrompe no seio de grupos insatisfeitos com os rumos da política do país ou da economia e que já não acreditam nas instituições, nem no diálogo e muito menos em mudanças sociais significativas” (BOFF, 2014, p. 01).

Historicamente, as práticas terroristas podem ser vislumbradas como ferramenta de ação de grupos radicais desde a antiguidade clássica, conforme preconiza a citação abaixo transcrita:

Os antigos assírios já cortavam as árvores e envenenavam os poços de água dos inimigos - numa região desértica isso era muito grave. Mas no século XX, isso assumiu proporções de política de Estado e atingiu de forma espetacular, dada a própria globalização, proporções até então nunca vistas na História. Essa é a exclusividade do século XX: o caráter espetacular do terrorismo de massas (MAIA, 2007, p. 01).

Hobsbawm (1978) observa a globalização do terrorismo desde os anos de 1970, dada a facilidade de uma publicidade inaudita sobre a ação. Em um primeiro momento, o processo atingia a espetacularização via imprensa escrita e falada, fosse através do rádio ou da televisão. Posteriormente, a internet facilitou ainda mais a disseminação das ações e das práticas que envolvem o terrorismo, sendo inclusive instrumento para que grupos terroristas disseminem a sua mensagem através do globo.

Eric Hobsbawm, no entanto, não considera o terrorismo como fato generalizado, pois: "Não há muito em comum, se quisermos tomar como exemplo os casos extremos, entre molucanos do sul da Holanda e as Brigadas Vermelhas na Itália. Mas ambos tem a mesma facilidade de comunicação mundial.” (HOBSBAWM, 1979, p. 26). Seguindo prerrogativas de pensamento que se alinham a Leonardo Boff, o autor inglês entende que os terroristas vivem na medida da publicidade e do espetáculo e quando alguns jovens não conhecem outra atividade política fértil e positiva recorrem a essa alternativa, pois leem, ouvem e veem o espetáculo. Hoje há uma enorme amplificação dos atos e certa ligação direta entre os terroristas através dos meios de comunicação.

Este mesmo autor observa que a base social do terrorismo, sobretudo na Europa, é composta de filhos da classe média e isso se evidenciou nos membros recrutados pela Fração 
do Exército Vermelho na Alemanha. Com a crise geral do capitalismo afluem ao terrorismo grupo de jovens desocupados, inclusive compostos de operários:

A afluência maciça à universidade (...) e graças à qual puderam atingir o mais alto nível de instrução dos filhos de famílias semianalfabetas, não pode deixar de ter consequências. Novos setores incorporaram às classes médias. Nessa marginalização, desenvolveu-se uma zona de recrutamento de terrorismo. Mas, o núcleo fundamental é a classe média. Basta ver o estilo das operações, a desenvoltura com que são usados todos os meios característicos da affluent society: automóveis, rádio, computadores etc. É um estilo de quem vive bem." (1978, p. 28).

A questão apontada por Hobsbawm conversa diretamente com a tese de Guy Debord (2003) na qual a desordem ${ }^{4}$ expressa de forma clara à maneira como o mundo ocidental evoluiu dentro do contexto capitalista. Ou seja, construiu-se uma ideologia envolta em preceitos democráticos, mas que ao fím e ao cabo é submetida “(...) à liberdade ditatorial do mercado, temperada pelos Direitos do homem espectador" (DEBORD, 2003, p. 09).

São essas "falhas" produzidas dentro do contexto espetacular que levariam jovens de classe média a participar de ações terroristas. Além disso, de acordo com Bauman, alguns outros fatores são elementares para o entendimento desta lógica, tais como:

Não [há] mais grandes líderes para lhe dizer o que fazer e para aliviálo da responsabilidade pela consequência de seus atos; no mundo dos indivíduos há apenas outros indivíduos cujo exemplo seguir na condução das tarefas da própria vida, assumindo toda a responsabilidade pelas consequências de ter investido a confiança nesse e não em qualquer outro exemplo (BAUMAN, 2001, p. 39)

Bauman reforça a ideia da fluidez contemporânea dos modos de estar no mundo, a qual perpassa a ausência de laços comunitários e de identificações sólidas. Esta liquidez também se faz sentir quando a assuntos são as questões que envolvem a(s) identidade(s), as quais na opinião do autor criam “(...) no fundo de nossas mentes, uma tênue imagem de harmonia, lógica, consistência: todas as coisas que parecem - para nosso desespero eterno faltar tanto e tão abominavelmente ao fluxo de nossa experiência (BAUMAN, 2001, p. 97).

\footnotetext{
$4 \quad$ Entendemos a lógica do terrorismo como uma desordem no sentido de que ela vai contra a ordem imposta pela terminologia vivenciada pela sociedade contemporânea a qual, per se, preconiza sua ação organizada tendo como parâmetro os Estados Nacionais e suas políticas, bem como o modo de produção capitalista e suas relações de mercado. Neste contexto, a ideia corresponde aos conceitos de Debord como propostos em "A Sociedade do Espetáculo".
} 
Para o autor, realizar esta busca pela identidade é uma forma de tentar deter ou pelo menos tornar mais lento o processo de fluidez característico da pós-modernidade. Nesse sentido, a lógica que impera é exatamente a de tentar devolver a forma àquilo que está disforme (no caso a práxis que envolve o ser no mundo ocidental) (BAUMAN, 2001). Essa fluidez é assustadora, pois ela não garante elementos ditos confiáveis e que sejam capazes de guiar protocolos de ação/relação entre os sujeitos. Mas acontece que, ao fim e ao cabo, todo o processo torna-se vão porque:

[...] as identidades, que não tornam o fluxo mais lento e muito menos o detêm, são mais parecidas com crostas que vez por outra endurecem sobre a lava vulcânica e que se fundem e dissolvem novamente antes de ter tempo de esfriar e fixar-se (BAUMAN, 2001, p. 97).

Essa tentativa de solidificar os laços identitários contraria a dinâmica das forças em jogo, as quais antes da liquefação eram ordenadoras e permitiam o reenraizamento e reencaixe dos antigos sólidos em novas configurações sociais modernas. Na atualidade essas referências tornaram-se liquefeitas o que pode ser exemplificado a partir da implosão de referências como as ideias de classe, de Estado-nação, de cidadania; e esse "derretimento dos sólidos", enquanto traço da modernidade ou da pós-modernidade aduziu a outros sentidos conforme nos expõe Bauman:

[...] um novo sentido, e, mais que tudo, foi redirecionado a um novo alvo, e um dos principais efeitos desse redirecionamento foi a dissolução das forças que poderiam ter mantido a questão da ordem e do sistema na agenda política. Os sólidos que estão para ser lançados no cadinho e os que estão derretendo neste momento, o momento da modernidade fluida, são os elos que entrelaçam as escolhas individuais em projetos e ações coletivas - os padrões de comunicação e coordenação entre as políticas de vida conduzidas individualmente, de um lado, e as ações políticas de coletividades humanas, de outro (BAUMAN, 2001, p. 12).

O mundo líquido promoveu a perda dos padrões de referências dos códigos sociais e culturais que permitiam as pessoas construírem suas vidas. Nesse sentido, as condições que anteriormente favoreciam aos sujeitos a constituição da cidadania passam por um processo de fragmentação. Em uma sociedade cada vez mais seletiva econômica e socialmente, os indivíduos passam a lutar por sua própria conta e risco enquanto condição de inserção no meio social (BAUMAN, 2001). Eis que brota a insegurança desses indivíduos cujo antídoto foca-se na identidade. 
A busca pela solidez/segurança oferecida por esta ideia de identidade “(...) é cheia de som e de fúria" (BAUMAN, 2003, p. 21). Isso acontece porque a prerrogativa relacionada ao sentido de identificar-se aponta para as singularidades que dividem e separam; para as dimensões que nos fazem diferente dos demais grupos, assim como na antiguidade clássica, os hebreus desenvolveram um código pautado no higienismo que os tornava diferente dos demais povos ao seu redor (SCLIAR, 2007). Nesses "cabides" representados pela ideia de identidade (sólida) os sujeitos podem:

[...] pendurar seus medos e ansiedades individualmente experimentados e, depois disso, realizar os ritos de exorcismo em companhia de outros indivíduos também assustados e ansiosos. É discutível se essas "comunidades-cabide" oferecem o que se espera que ofereçam - um seguro coletivo contra incertezas individualmente enfrentadas; mas sem dúvida marchar ombro a ombro ao longo de uma ou duas ruas, montar barricadas na companhia de outros ou roçar os cotovelos em trincheiras lotadas, isso pode fornecer um momento de alívio da solidão (BAUMAN, 2003, p. 21).

Daí que se arrazoa que uma das motivações para aderir a agrupamentos terroristas resida no alívio da solidão e das incertezas que a crise da modernidade trouxe consigo. Daí a busca por ídolos capazes de atestar a experiência comum de fluidez devido à instabilidade na construção da vida individualizada. Assim, seguir determinadas lideranças possibilita viver um sonho de fazer parte, o que não quer dizer que ele também não se desvaneça com rapidez.

Bauman, em sua obra "Medo Líquido" expõe a fragilidade dos laços humanos, das identidades que desnudam um mundo de incertezas e medos. Para o autor a vulnerabilidade que atinge o mundo como um todo contemporaneamente é complexa justamente pelo fato de que não temos condições efetivas de calcular os riscos que envolvem a vida cotidiana. Para ele:

Possivelmente, o tipo atual de incerteza planetária tende a permanecer incurável até que a globalização negativa seja suplementada e controlada pela positiva e que as probabilidades se tornem mais passíveis de cálculo. As raízes de nossa vulnerabilidade são de natureza política e ética (BAUMAN, 2008, p. 129).

A desestabilização das pessoas em suas emoções e sensações de falta de segurança as leva a desconfiar ainda mais de gestos ou de indivíduos estranhos. Nesse sentido, Boff entende que essa desestabilização perpassa a seguinte estratégia terrorista:

(1) os atos têm de ser espetaculares, caso contrário, não causam comoção generalizada; 
(2) os atos, apesar de odiados, devem provocar admiração pela sagacidade empregada;

(3) os atos devem sugerir que foram minuciosamente preparados;

(4) os atos devem ser imprevistos para darem a impressão de serem incontroláveis;

(5) os atos devem ficar no anonimato dos autores (usar máscaras) porque quanto mais suspeitos, maior o medo;

(6) os atos devem provocar permanente medo;

(7) os atos devem distorcer a percepção da realidade: qualquer coisa diferente pode configurar o terror. Basta ver alguns rolezinhos entrando nos shoppings e já se projeta a imagem de um assaltante potencial (BOFF, 2014, p. 2).

Salienta-se que nesta discussão, as transformações também são rápidas embora alguns grupos atuem com características clássicas apontadas neste texto, porém com outras estratégias imbuídas de maior agressividade denominadas como neoterrorismo internacional. Os adeptos geralmente se submetem a treinamentos em campos de recrutamento e suas ações em sua maioria são ataques suicidas buscando um crescente número de vítimas quer seja com bombas ou outras táticas como o uso de outras armas e veículos. Outra característica desse terrorismo é a organização descentralizada, ou seja, não possuem território fixo e nem alvo definido.

Outra dimensão da temática refere-se aos estereótipos da mass media ocidental auferidos aos atentados envolvendo não ocidentais, ou seja, o tratam como um fato comum no Oriente ou da cultura islâmica como se fosse o lar de todos os terroristas, um lugar da tirania e do atraso associados a irracionalidade. Boff assim pontua um dos efeitos dessa instabilidade causada por ações terroristas:

Um dos efeitos mais lamentáveis do terrorismo foi ter suscitado o Estado terrorista como os EUA. Criou-se uma legislação que fere os direitos humanos, impõe vigilância sobre toda a população, criou o organismo de segurança nacional com altas verbas para sua implantação em todo o pais, projetou a "guerra infinita" contra o terrorismo em qualquer parte do mundo com a ameaça de utilização de qualquer tipo de arma, não excluídas as armas nucleares. E organizou uma rede de espionagem eletrônica global que tudo e a todos controla (BOFF, 2014, p. 3).

Daí a necessidade dessas discussões para compreendermos estas visões plurais, dicotômicas e, por vezes, equivocadas evitando abordagens que pouco contribuem para 
entender as especificidades dos atos e grupos e, sobretudo, focar nas relações socioculturais, políticas e nos agenciamentos destes sujeitos e grupos terroristas.

Para Boff, mais relevante não é saber quem cometeu e comete atos de terrorismo, mas saber o porquê se recorre a ele. "Ai a importância do acompanhamento dos órgãos de informação, do diálogo aberto com todos os estratos da sociedade, especialmente, com aqueles mais penalizados pelo tipo de sociedade que temos, altamente desigual e discriminatória.” (BOFF, 2014, p. 4). Para Bauman, a globalização negativa deveria ser controlada e domada de modo a evitar um cataclismo inescapável. Essa possibilidade pode se concretizar através de um novo pacto entre os intelectuais e a população, numa injunção de esforços negociados.

\section{Referências}

ALVES, José Augusto Lindgren. 1995: Direitos Humanos em "Sursis”. In: Lua Nova Revista de Cultura Política, no 35, 1995, p. 149-167.

BAUMAN, Zygmunt. Modernidade Líquida. Jorge Zahar Editor, 2001.

BAUMAN, Zygmunt. Medo líquido. Rio de Janeiro: Jorge Zahar Ed., 2008.

BOBBIO, Norberto et al. Dicionário de Politica. Brasília/São Paulo, UnB/Imprensa Oficial, 2000, p.1252-1254.

BOFF, Leonardo. Por uma definição de terrorismo. In: https://leonardoboff.wordpress.com/2014/02/14/para-uma-definicao-do-terrorismo/ Acesso em janeiro de 2016.

CHOMSKY, N. 11 de setembro. Rio de Janeiro: Bertrand Brasil, 2002.

DEBORD, Guy. A Sociedade do Espetáculo. eBooksBrasil.com, 2003. In: https://www.marxists.org/portugues/debord/1967/11/sociedade.pdf, acesso em 15 de junho de 2017, às 15 h e 34 min.

FERREIRA, Aurélio Buarque de Holanda. Dicionário Aurélio. Editora Nova Fronteira, Rio de Janeiro, 1988. 
GUATTARI, Feliz. Caosmose: um novo paradigma estético. Trad. Ana Lúcia de Oliveira e Lúcia Cláudia Leão. 2 ed. São Paulo: 34, 2012. (Coleção TRANS).

HALL, Stuart. A identidade cultural na pós-modernidade. 11 ed, Rio de Janeiro: DP\&A Editora, 2006.

HOBSBAWM, Edward. Globalização, democracia e terrorismo. São Paulo: Cia das Letras, 2007.

HOBSBAWM, Eric. Terrorismo Global. In: Encontros com a Civilização Brasileira. Rio de Janeiro: Civilização Brasileira, n.1, julho 1978, p. 25-28.

LEVY, Pierre. Cibercultura. São Paulo: Ed. 34, 1999.

LÉVY, Pierre. O que é o virtual?. 2 ed, São Paulo: Editora 34, 2011.

MAIA, Mônica. Historiadores da UFRJ produzem mapa do terrorismo mundial. In: http://www.faperj.br/?id=1042.2.4 Acesso em janeiro de 2015.

SCLIAR, Moacyr. História do Conceito de Saúde. In: Physis Rev. de Saúde Coletiva, Rio de Janeiro, 17(1): p. 29-41, 2007. 